\title{
USE OF RECYCLED CONCRETE AGGREGATE IN CONCRETE: A REVIEW
}

\author{
Md. SAFIUDDIN ${ }^{\mathrm{a}}$, Ubagaram Johnson ALENGARAM ${ }^{\mathrm{b}}$, Md. Moshiur RAHMAN ${ }^{\mathrm{b}}$, \\ Md. Abdus SALAM ${ }^{\mathrm{b}}$, Mohd. Zamin JUMAAT ${ }^{\mathrm{b}}$ \\ ${ }^{a}$ School of Construction Management and Trades, Centre for Construction and Engineering Technologies, \\ George Brown College, Casa Loma Campus, 160 Kendal avenue, Toronto, ON M5R 1M3, Canada \\ ${ }^{b}$ Department of Civil Engineering, Faculty of Engineering, University of Malaya, 50603 Kuala Lumpur, \\ Malaysia
}

Received 30 Oct 2011; accepted 16 Jan 2012

\begin{abstract}
The use of recycled concrete aggregate (RCA) in concrete as partial and full replacements of natural coarse aggregate is growing interest in the construction industry, as it reduces the demand for virgin aggregate. In addition, the use of RCA leads to a possible solution to the environmental problem caused by concrete waste and reduces the negative environmental impact of the aggregate extraction from natural resources. This paper presents a comprehensive review on the use of RCA in concrete based on the experimental data available in the published research. The most important physical, mechanical, and chemical properties of RCA are discussed in this paper. However, more emphasis has been given to discuss the effects of RCA on the fresh and hardened properties and durability of concrete. This paper also identifies the gaps existing in the present state of knowledge on RCA and RCA concrete and provides some recommendations for future research
\end{abstract}

Keywords: concrete; natural coarse aggregate; recycled concrete aggregate; fresh properties; hardened properties; durability.

Reference to this paper should be made as follows: Safiuddin, M.; Alengaram, U. J.; Rahman, M. M.; Salam, M. A.; Jumaat, M. Z. 2013. Use of recycled concrete aggregate in concrete: a review, Journal of Civil Engineering and Management 19(6): 796-810. http://dx.doi.org/10.3846/13923730.2013.799093

\section{Introduction}

Demolition of old structures and construction of new ones are frequent phenomena due to change of purpose, structural deterioration, rearrangement of a city, expansion of traffic directions, and natural disasters. About 850 million tons of construction and demolition waste are generated in the European Union each year, which represents $31 \%$ of the total waste generation (Malešev et al. 2010). In the USA, the waste produced from building demolition alone is approximately 123 million tons per year (Malešev et al. 2010). There are no available data on the current amount of solid waste generation in Malaysia. In 2005, the total solid waste generated in Malaysia was $6,971,500$ tons at a rate of 19,100 tons per day (Siwar 2008). Moreover, Hassan et al. (1998) reported that the industrial and construction wastes form about $28.34 \%$ of the total solid waste in the Central and Southern region of Malaysia. These data reveal that a significant portion of the total solid waste generated in Malaysia is construction waste (returned or unused concrete, demolished concrete, etc.). Globally, a vast amount of concrete waste is derived from the demolition of old concrete structures. Most commonly this concrete waste is disposed to landfills, thus causing substantial environmental load and health hazard (Malešev et al. 2010). Furthermore, the shortage of land and the increasing charges for landfills worsen this environmental problem. The utilization of concrete wastes in sustainable development may alleviate such problems.

Sustainable development is presently a major issue all over the world. The concept of sustainable development was first presented at the 1992 Earth Summit in Rio de Janeiro city of Brazil (Limbachiya et al. 2004), and now it has become a guiding principle for the construction industry worldwide. The recycling and reuse of concrete waste can be an effective way to achieve sustainability in the construction sector. In fact, many governments throughout the world have recently introduced various measures aimed at reducing the use of natural aggregates and increasing the recycling of concrete waste for reuse as aggregates wherever it is technically, economically, or environmentally acceptable (Limbachiya et al. 2004).

Aggregates form the skeleton for concrete. They usually occupy about $70 \%$ of the total volume of 
concrete (ACPA 2009). A major portion of this aggregate volume is occupied by coarse aggregates. Therefore, the demand for coarse aggregates is enormous in the construction industry. The increased extraction of coarse aggregates from the natural resources is required to meet this high demand. The increasing use of natural coarse aggregate (NCA) creates an ecological imbalance. Thus, the use of alternative coarse aggregates is vital in construction industry. One of the means to achieve this is to use the recycled concrete aggregate (RCA) obtained from the demolished concrete structures. The use of RCA in construction reduces the need for NCA, which in turn reduces the negative environmental impact due to the extraction of virgin aggregates. The scarcity of NCA and the increasing charges for landfill have also encouraged the use of RCA in concrete. Besides, the increased distance between the sources of quality natural aggregates and construction sites has constrained the contractors to consider substituting NCA by RCA (Grdic et al. 2010).

Research works commenced more than 30 years ago to investigate the properties of RCA and new concrete including RCA (Frondistou-Yannas 1977). Most investigations conducted in the past were largely limited to the manufacture of non-structural grade RCA concrete due to undesirable physical properties of RCA, such as high water absorption that increases water demand for a given workability. However, structural grade concrete can also be produced using RCA. According to Shayan and Xu (2003), the use of RCA in high-strength and highperformance structural concretes is possible with the addition of silica fume and through proper mix design and quality control. Levy and Helene (2004) and Poon et al. (2003) have graded RCA as potentially good for use in structural concrete. Moreover, Hendriks and Pieterson (1998) and Tu et al. (2006) reported that RCA can be used to produce durable and sustainable concretes. Whether used in non-structural or structural grade concrete, RCA provides environmental benefits by reducing the disposal load on landfill sites and conserving natural rock resources that are currently being depleted to produce NCA.

This paper collates the research findings published to date regarding the use of RCA in concrete and provides a general review of its effects on concrete properties. Based on the available experimental evidence, the major properties of RCA and RCA concrete are discussed in this paper. Although many research works have been conducted in this area, still there are significant gaps in the current state of knowledge on RCA and RCA concrete. This paper identifies these knowledge gaps and presents a number of research needs for future investigations.

\section{Properties of RCA}

\subsection{Physical properties}

The physical properties of RCA influence the mix proportion and properties of concrete. The basic characteristics such as shape and texture, specific gravity, bulk density, pore volume, and absorption of RCA are generally worse than those of NCA due to the presence of residual cement paste/mortar and impurities (SagoeCrentsil et al. 2001; Tu et al. 2006). The magnitude of the effects varies with the nature and quantity of reclaimed cement paste/mortar that is present in RCA (ACPA 2009). The basic physical properties of RCA summarized from the available literature (Hansen 1992; ECCO 1999; González-Fonteboa, Martínez-Abella 2008; Anderson et al. 2009; Safiuddin et al. 2011a) are shown in Table 1 and discussed hereafter.

\subsubsection{Particle shape and texture}

RCA tends to be very angular and rough due to the crushing of old concrete and because of the presence of hardened cement paste/mortar adhered to the surfaces of original coarse aggregate. Typically, RCA particles contain $30-60 \%$ old cement paste/mortar, depending on the aggregate size (ECCO 1999). A greater amount of old cement paste/mortar is attached to the smaller size fractions of coarse aggregate. RCA is similar to crushed rock in particle shape, but the type of crushing equipment influences the gradation and other characteristics of crushed concrete.

\subsubsection{Specific gravity}

The specific gravity of RCA is usually lower than that of NCA (Hansen 1992; Yong, Teo 2009). The lower specific gravity of RCA is due to the presence of old cement paste/ mortar on the aggregate particles that makes it less dense than NCA because of greater porosity (Anderson et al. 2009). The typical values of specific gravity of RCA range from 2.1 to 2.5 in the saturated surface-dry condition

Table 1. Basic physical properties of NCA and RCA

\begin{tabular}{lll}
\hline Physical property & \multicolumn{1}{c}{ NCA } & \multicolumn{1}{c}{ RCA } \\
\hline Shape and texture & $\begin{array}{l}\text { Well rounded, smooth (gravels) to } \\
\text { angular and rough (crushed rock) }\end{array}$ & Angular with rough surface \\
Specific gravity (saturated surface-dry based) & $2.4-2.9$ & $2.1-2.5$ \\
Bulk density (compacted) $\left(\mathrm{kg} / \mathrm{m}^{3}\right)$ & $1450-1750$ & $1200-1425$ \\
Absorption (wt. \%) & $0.5-4$ & $3-12$ \\
Pore volume (vol. \%) & $0.5-2$ & $5.0-16.5$ \\
\hline
\end{tabular}


(Table 1) that are $5-10 \%$ lower than that of NCA (ECCO 1999).

\subsubsection{Bulk density}

The bulk density of RCA is significantly lower than that of NCA (Hansen 1992; Juan, Gutierrez 2004), as evident from Table 1. According to the experimental results of Yong and Teo (2009), the bulk density of RCA has been found to be $9.8 \%$ lower than that of natural gravel aggregate. This is mostly due to the higher porosity of $\mathrm{RCA}$ in the presence of adhered cement paste/mortar.

\subsubsection{Pore volume}

The pore volume of RCA is substantially higher than that of NCA (Table 1). This is due to the porous nature of adhered cement paste/mortar originated from old concrete (González-Fonteboa, Martínez-Abella 2008; Safiuddin et al. 2011a). The higher pore volume of RCA makes it weak and less dense, as compared to NCA.

\subsubsection{Absorption}

The absorption of RCA is significantly higher than that of NCA (Rahal 2007; Evangelista, de Brito 2007; Yang et al. 2008), as can be seen from Table 1 . When demolished concrete is crushed, a certain amount of cement paste/ mortar from the original concrete remains attached to RCA particles. The attached cement paste/mortar possesses a greater porosity than the original aggregate; this is the main reason for the higher absorption of RCA.

\subsection{Mechanical properties}

The mechanical properties of concrete depend on the mechanical properties of aggregate. From the available literature, it was found that the mechanical properties of RCA are inferior to those of NCA (Hansen 1992; ECCO 1999; Poon et al. 2003; López-Gayarre et al. 2009; Malešev et al. 2010). The key mechanical properties of NCA and RCA are shown in Table 2 and briefly discussed hereafter.

\subsubsection{Aggregate abrasion value}

The aggregate abrasion value (AAV) is a measure for the wear resistance of aggregate. A higher AAV is obtained when the loss of material due to wear becomes greater. The AAV of RCA is usually higher than that of NCA. The typical Los Angeles abrasion values of RCA range from $20 \%$ to $45 \%$, which are higher than those of

Table 2. Key mechanical properties of NCA and RCA

\begin{tabular}{lll}
\hline Mechanical property (wt. \%) & NCA & RCA \\
\hline Aggregate abrasion value & $15-30$ & $20-45$ \\
Aggregate impact value & $15-20$ & $20-25$ \\
Aggregate crushing value & $14-22$ & $20-30$ \\
\hline
\end{tabular}

NCA (Hansen 1992; ECCO 1999; Poon et al. 2003; López-Gayarre et al. 2009) (Table 2). However, the AAV of RCA is generally below the acceptable maximum limit (50\% by weight) for structural applications, irrespective of its origin (Tabsh, Abdelfatah 2009).

\subsubsection{Aggregate impact value}

The aggregate impact value (AIV) is a strength value of aggregate subjected to impact. AIV indicates the resistance of aggregate to dynamic load. The higher the AIV, the weaker is the aggregate. It has been found from the previous studies that the AIV of RCA (20-25\%) is greater than that of NCA (15-20\%) (Table 2). The attached mortar and cement paste make RCA less strong, and therefore result in a greater AIV for RCA.

\subsubsection{Aggregate crushing value}

The aggregate crushing value (ACV) provides a measure for the resistance of aggregate to crushing under gradually applied compressive load. The lower the value, the stronger is the aggregate. From the available literature, it has been found that the ACV of RCA $(20-30 \%)$ is considerably higher than that of NCA (14-22\%) (Table 2). This is expected because of the relatively weak cement paste and mortar attached to RCA particles (Malešev et al. 2010).

\subsection{Chemical properties}

The performance of RCA concrete is influenced by the chemical properties of RCA. If the deleterious chemicals such as alkalis, sulphates, and chlorides are present in RCA, the durability of concrete will be affected. The chemical properties of RCA are briefly discussed below.

\subsubsection{Soundness}

Soundness of aggregate is an indication of aggregate's resistance to weathering and other environmental effects (Anderson et al. 2009; Tabsh, Abdelfatah 2009). Sodium sulphate and magnesium sulphate soundness tests are generally used to assess the soundness of aggregate. RCA commonly fails sodium sulphate soundness test, but passes magnesium sulphate soundness test (Snyder, Vandenbossche 1993; Anderson et al. 2009). The magnesium sulphate soundness losses obtained by Poon and Chan (2007) were $2.5 \%$ and $3.7 \%$ for NCA and RCA, respectively. These values are similar to the results obtained by Anderson et al. (2009). Tabsh and Abdelfatah (2009) investigated sodium sulfate soundness test and found that the losses were $9 \%$ and $12 \%$ for NCA and RCA, respectively, and thus met the requirement specified by ASTM C 33-04 (2004). These results are also similar to those obtained by Anderson et al. (2009). The unsoundness of RCA is mostly related to the pore size distribution in the aggregate (Anderson et al. 2009). 


\subsubsection{Alkali-aggregate reactivity}

RCA may cause an alkali-aggregate reaction (AAR) in concrete if the aggregates of original concrete were susceptible to AAR (Hansen 1986; Stark 1996). In addition, the alkali content of cement paste or mortar adhered to RCA might have significant effect on the AAR susceptibility of new concrete containing RCA. The alkali content of RCA is related to its mortar content. An RCA possessing a greater amount of mortar results in a higher alkali content (Juan, Gutierrez 2004), and therefore it is more prone to AAR.

\subsubsection{Sulphate content}

RCA can have a higher sulphate content due to sulphate compounds present in the cement of adhered mortar (Juan, Gutierrez 2004). Poon and Chan (2007) examined the water soluble sulphate content for NCA and RCA; they obtained 0.025 and $0.032 \mathrm{~g} / \mathrm{L}$ sulphate content for NCA and RCA, respectively. The sulphate content of RCA depends on the quantity of adhered cement paste/mortar. A higher sulphate content of RCA reveals that a greater amount of mortar is attached to RCA (Juan, Gutierrez 2004).

\subsubsection{Chloride content}

High chloride levels have been found in the RCA produced from the sources with long-term exposure to chloride-based deicing chemicals. The RCA with high chloride contents may affect the durability of new concrete due to the corrosion of steel reinforcement (Anderson et al. 2009). The RCA derived from the old concrete containing chlorides more than $0.04 \mathrm{~kg} / \mathrm{m}^{3}$ should not be used in new concrete, because the accelerated steel corrosion could lead to the early failure of reinforced concrete structure (Anderson et al. 2009).

\subsubsection{Organic matter}

Paper, wood, textile fabrics, joint seals, plastics, rubber, and other polymeric materials can be present in RCA. These materials become unstable in concrete when subjected to drying and wetting or freezing and thawing (Khalaf, DeVenny 2004). The acceptable limit of organic matter in concrete is $0.15 \%$ by weight of RCA (ECCO 1999).

\section{Properties of RCA concrete}

\subsection{Fresh properties}

RCA can influence the properties of fresh concrete due to its greater angularity, surface roughness, absorption, and porosity. The effects of RCA on the key fresh properties of concrete, as observed from the available literature (Shayan, Xu 2003; Nelson 2004; Poon et al. 2004; González-Fonteboa, Martínez-Abella 2008; Yang et al. 2008; Kou, Poon 2009; Abbas et al. 2009; Grdic et al. 2010; Safiuddin et al. 2011b), are given in Table 3 and discussed below.
Table 3. Fresh properties of NCA and RCA concretes

\begin{tabular}{lll}
\hline Fresh property & \multicolumn{1}{c}{$\begin{array}{c}\text { NCA } \\
\text { concrete }\end{array}$} & $\begin{array}{c}\text { RCA } \\
\text { concrete }\end{array}$ \\
\hline $\begin{array}{l}\text { Workability } \\
\text { Slump (mm) }\end{array}$ & $90-275$ & $70-255$ \\
$\begin{array}{l}\text { Slump flow (mm) } \\
\text { Slump loss for normal concrete } \\
\text { (after 45 min) (\%) }\end{array}$ & $500-735$ & $380-725$ \\
$\begin{array}{l}\text { Slump loss for self-consolidating } \\
\text { concrete (after 1 h) (\%) }\end{array}$ & $2.4-2.6$ & 75 \\
$\begin{array}{l}\text { Stability (segregation resistance) } \\
\text { Visual stability index, VSI }\end{array}$ & & \\
(based on bleeding, mortar & $\mathrm{VSI}_{\mathrm{NCA}} \leq 1$ & $\mathrm{VSI}_{\mathrm{RCA}}<<1$ \\
halo, and aggregate piling) & & \\
$\begin{array}{l}\text { Sieve segregation (\%) } \\
\text { Wet density ( } \mathrm{kg} / \mathrm{m}^{3} \text { ) }\end{array}$ & $8.9-10.4$ & $8.3-12.3$ \\
Air content $(\%)$ & $2325-2455$ & $2250-2370$ \\
\hline
\end{tabular}

${ }^{\mathrm{a}} \mathrm{A}$ lower VSI value indicates higher stability or segregation resistance.

\subsubsection{Workability}

The greater angularity and surface roughness of RCA particles decrease the workability of concrete and make it more difficult to finish properly (Yrjanson 1989). The degree of decrease in workability increases with the increased percentage of RCA in the concrete mix (Topçu, Günçan 1995). Therefore, additional water is required for RCA concrete to obtain the same workability of NCA concrete.

The concrete mixes incorporating RCA generally satisfy the initial slump requirements (Mukai et al. 1979; Su, Wang 2000; Tu et al. 2006), as can be seen from Table 3. However, the higher absorption of RCA can lead to a rapid loss of workability (Table 3 ), thus limiting the time needed for placing and finishing of concrete. The problems associated with the rapid loss of workability should be addressed by altering and controlling the moisture content of RCA before mixing, not by adding extra water at the jobsite (ACPA 2009).

\subsubsection{Stability}

The bleeding of RCA concrete is generally less than that of NCA concrete (Mukai et al. 1979; Hansen, Narud 1983). This is because some of the old mortars rub off RCA during mixing and produce additional fines in the concrete mix. These fines adsorb some of the mix water and thus reduce the bleeding in concrete. The greater amount of fines also increases the cohesiveness of the concrete mix at lower free water content. In addition, the increased angularity and surface roughness at a higher RCA content contribute to the increase in the cohesiveness of concrete (Safiuddin et al. 2011b). The stability of the concrete mix improves due to reduced bleeding and increased cohesiveness. Hence, the segregation resistance of RCA concrete can be comparable to that of NCA concrete (Table 3). 


\subsubsection{Wet density}

Several studies were carried out to investigate the effect of RCA on the wet density of concrete. The wet density of RCA concrete is generally lower than that of NCA concrete (Topçu, Günçan 1995; González-Fonteboa, Martínez-Abella 2008), as obvious from Table 3. It has been reported that the wet density of RCA concrete is $5-15 \%$ lower than that of NCA concrete (ECCO 1999). This is because RCA possesses adhered old mortar or cement paste whose density is lower than the density of NCA.

\subsubsection{Air content}

The concrete air content is greatly influenced by its mortar volume (Safiuddin et al. 2011c). RCA influences the concrete air content because it has a larger mortar content. The air content of the fresh concrete containing RCA is slightly more variable and often up to $0.6 \%$ higher than the air content of the fresh NCA concrete (Snyder, Vandenbossche 1993), as can be seen from Table 3. This is caused by the air that is entrained and entrapped in the reclaimed mortar of RCA (Wade et al. 1997). Hence, the air content of the existing mortar should be considered while deciding the target air content of RCA concrete.

\subsection{Hardened properties}

The effect of RCA on the hardened properties of concrete can be negligible or significant depending on its source, type, content, gradation, and physical properties. Generally, the hardened properties of RCA concrete decline with the replacement level of NCA by RCA. As a general principle, up to $30 \%$ (on weight basis) of NCA may be replaced by RCA without significantly affecting the hardened properties of concrete (ECCO 1999). The range of changes in the hardened properties of concrete due to RCA, as observed from the available literature (Hansen 1986, 1992; Chern et al. 1995; Hwang et al. 1996; Ajdukiewicz, Kliszczewicz 2002; Li, Hwang 2002; Juan, Gutierrez 2004; Rahal 2007; Evangelista, de Brito 2007; Yang et al. 2008; ACPA 2009; Anderson et al. 2009; Butler et al. 2011), are given in Table 4. The key hardened properties of RCA concrete are discussed below.

\subsubsection{Dry density}

The dry density of RCA concrete is typically $5-15 \%$ lower than that of NCA concrete (Hansen 1986). This is because of the reclaimed mortar attached to RCA. According to Hansen and Narud (1983), the amount of mortar attached to RCA varies in the range of $30-60 \%$ (by volume of RCA) depending on the size of aggregate. The density of reclaimed mortar is much lower than that of most virgin aggregates. This results in a lower density for RCA concrete.

\subsubsection{Compressive strength}

The compressive strength of RCA concrete is usually lower than that of NCA concrete as shown in Figure 1.
Table 4. Effect of RCA on the hardened properties of concrete

\begin{tabular}{ll}
\hline Property & Range of changes \\
\hline Dry density & $5-15 \%$ less \\
Compressive strength & $0-30 \%$ less \\
Splitting tensile strength & $0-10 \%$ less \\
Flexural strength & $0-10 \%$ less \\
Bond strength & $9-19 \%$ less \\
Modulus of elasticity & $10-45 \%$ less \\
Porosity & $10-30 \%$ more \\
Permeability & $0-500 \%$ more \\
Water absorption & $0-40 \%$ more \\
Chloride penetration & $0-30 \%$ more \\
Drying shrinkage & $20-50 \%$ more \\
Creep & $30-60 \%$ more \\
Thermal expansion & $10-30 \%$ more \\
\hline
\end{tabular}

Most commonly, the compressive strength of RCA concrete is $5-10 \%$ lower than that of NCA concrete (ACPA 2009). But it can also be decreased up to $25 \%$ depending upon the quality of RCA (Hansen 1992; Ajdukiewicz, Kliszczewicz 2002; Juan, Gutierrez 2004; Rahal 2007; Evangelista, de Brito 2007; Anderson et al. 2009). The higher air content normally found in the concrete mixes containing RCA may also lead to lower strength values (Anderson et al. 2009). However, RCA concrete may have the similar and sometimes higher compressive strength than NCA concrete if the RCA is derived from a source of old concrete, which was originally produced with a lower water to cement ratio than the new concrete (Padmini et al. 2009).

Mandal et al. (2002) and Limbachiya et al. (2000) found that RCA produced no effect on the compressive strength of concrete up to the replacement level of $30 \%$ by weight; but the compressive strength decreased for the RCA content more than $30 \%$. Poon et al. (2004) found that the compressive strength of concrete was much lower

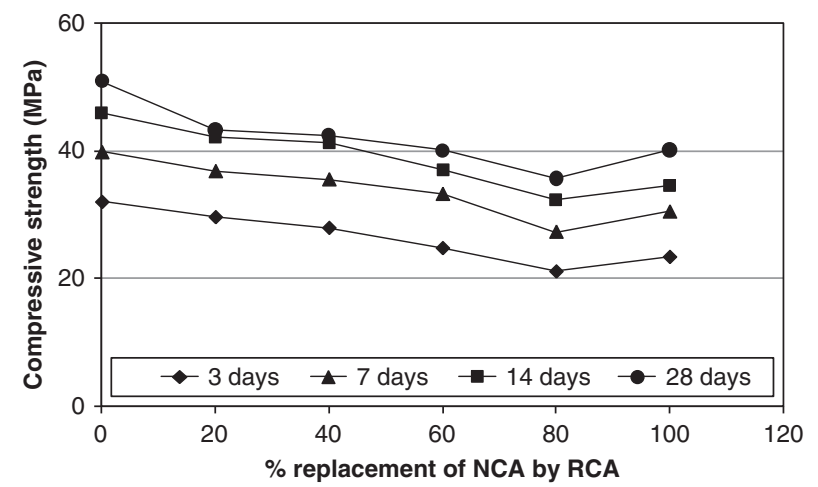

Fig. 1. Effect of RCA on the compressive strength of concrete (Nelson 2004) 
when RCA was used in the oven-dry state. In the case of high-performance concrete, $20-30 \%$ reduction in compressive strength was found due to the use of RCA (Chern et al. 1995; Hwang et al. 1996; Li, Hwang 2002). A similar result was observed by other researchers (SagoeCrentsil et al. 2001; Ajdukiewicz, Kliszczewicz 2002). Grdic et al. (2010) investigated the properties of selfcompacting concrete prepared with RCA and compared with those of NCA concrete; they observed that the difference in compressive strength at the same age was not significant.

The fine RCA can also affect the compressive strength of concrete. According to Tavakoli and Soroushian (1996), the compressive strength of RCA concrete is influenced by the coarse aggregate to fine aggregate ratio of the source concrete of RCA. The lower coarse to fine aggregate ratio leads to a higher quantity of mortar attached to coarse RCA particles and thus results in a reduction in the strength of RCA concrete. This reduction is even greater when recycled fines are used, and therefore the use of fine RCA in concrete is generally not recommended (Anderson et al. 2009; Malešev et al. 2010). However, according to Dhir et al. (1999), no decrease in compressive strength occurred for the concrete containing up to $20 \%$ fine RCA; beyond this level, the strength decreased with an increase in the RCA content.

\subsubsection{Splitting tensile strength}

Limited literature is available concerning the effect of RCA on the splitting tensile strength of concrete. Nelson (2004) reported that the splitting tensile strength of RCA concrete is lower than that of NCA concrete, as shown in Figure 2. Several researchers observed that the splitting tensile strength of RCA concrete is $0-10 \%$ lower than that of NCA concrete, but no statistically significant reduction in the tensile strength occurred during the period of 91 to 365 days (Hansen 1992; Ajdukiewicz, Kliszczewicz 2002; Anderson et al. 2009). On the other hand, Tavakoli and Soroushian (1996) reported that RCA concrete produced higher splitting tensile strength than NCA concrete. Hence, more research is required to investigate the effect of RCA on the splitting tensile strength of concrete.

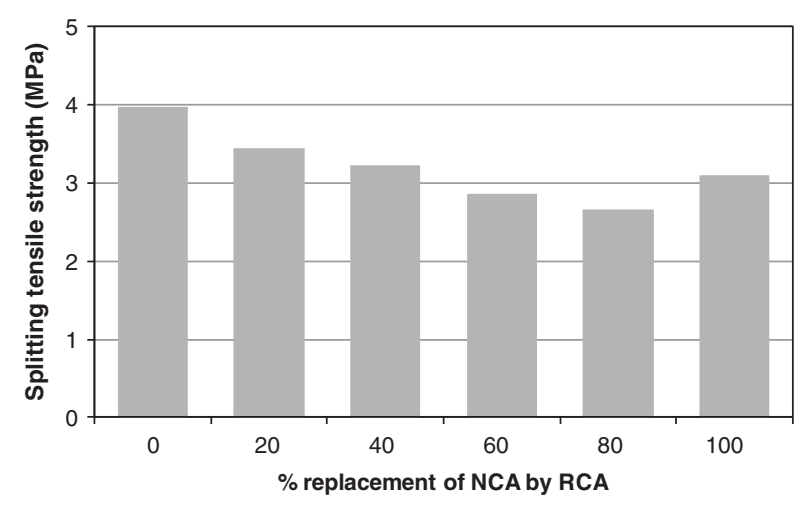

Fig. 2. Effect of RCA on the splitting tensile strength of concrete (Nelson 2004)

\subsubsection{Flexural strength}

The flexural strength of RCA concrete is generally lower than that of NCA concrete, as shown in Figure 3. The flexural strength of RCA concrete is typically $0-10 \%$ lower than that of NCA concrete (Hansen 1992; Ajdukiewicz, Kliszczewicz 2002; Yang et al. 2008). According to Yong and Teo (2009), the three-day flexural strength of RCA concrete was higher than that of NCA concrete; but the strength was lower at the age of 28 days. In their study, the NCA concrete gained strength gradually and had a higher flexural strength than RCA concrete at later age. Safiuddin et al. (2011a) reported that RCA did not produce any significant negative impact on the flexural strength of concrete. Nevertheless, RCA concrete with adequate flexural strength can be produced for different applications, sometimes even with $100 \%$ replacement of NCA (Yrjanson 1989; ACI 555R-01 2001).

\subsubsection{Bond strength}

The bond strength of concrete is an indication of the interlocking characteristic of aggregate and paste. The rough surface of RCA results in a better bond than NCA (Khalaf, DeVenny 2004). Malešev et al. (2010) used $\varnothing 100 \times 150 \mathrm{~mm}$ cylindrical specimens with embedded ribbed and mild reinforcement (embedded length: $150 \mathrm{~mm}$, diameter: $12 \mathrm{~mm}$ ) for testing the bond between reinforcement and concrete including $0 \%, 50 \%$, and $100 \%$ RCA. The results showed that the bond between RCA concrete and reinforcement is not significantly influenced by the inclusion of RCA in concrete. However, the results from Butler et al. (2011) revealed that the bond strength of NCA concrete was $9-19 \%$ higher than that of RCA concrete. Such contradictory results suggest that more research is required to investigate the effect of RCA on the bond strength of concrete.

\subsubsection{Modulus of elasticity}

An aggregate of higher elastic modulus increases the elastic modulus of concrete (Zhou et al. 1995). Because of weaker nature (lower strength), the elastic modulus of RCA is lower than that of NCA. Therefore, the concrete's

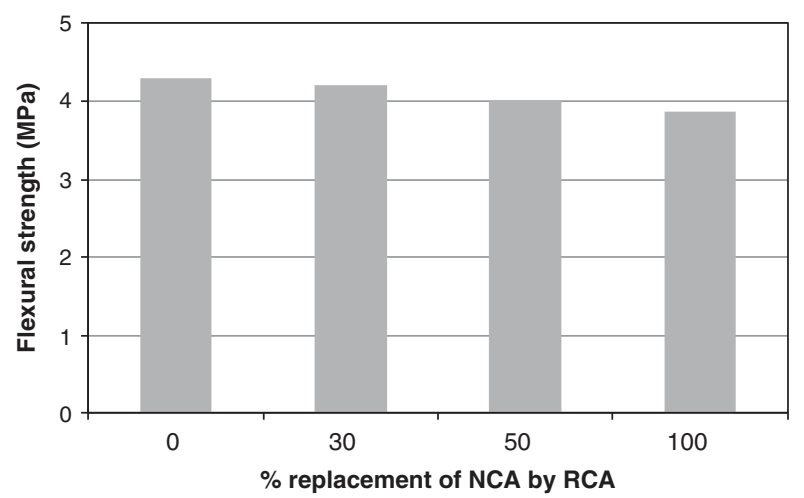

Fig. 3. Effect of RCA on the flexural strength of concrete (Yang et al. 2008) 
modulus of elasticity decreases with an increase in RCA content in concrete's (Nelson 2004), as shown in Figure 4.

The elastic modulus of concrete containing RCA is typically $10-33 \%$ lower than that of NCA concrete (Anderson et al. 2009). Corinaldesi (2010) showed that the use of $30 \%$ RCA in concrete produced about $15 \%$ reduction in elastic modulus. However, the elastic modulus of RCA concrete may be lower up to $45 \%$ as compared to NCA concrete (Ajdukiewicz, Kliszczewicz 2002; Rahal 2007; Yang et al. 2008). The reduction in the modulus of elasticity of concrete is due to the fact that RCA typically has a lower elastic modulus than NCA (ACPA 2009). The reduction in the elastic modulus of concrete is also attributed to the increased overall mortar content (new and reclaimed), which has a lower elastic modulus than most virgin aggregates.

\subsubsection{Porosity}

Limited studies have been found regarding the effect of RCA on the porosity of concrete. Levy and Helene (2004) made grade 20 to 40 concretes and showed that at $20 \%$ replacement of RCA, the total porosity was lower than that of the control concrete with NCA, as shown in Figure 5. They also observed that the total porosity was increased at $50 \%$ RCA content for all concretes. However, grade 20 RCA concrete at $100 \%$ replacement of NCA had a slightly lower porosity than the grade 20 NCA concrete. According to Levy and Helene (2004), the porosity of RCA concrete can be $10-30 \%$ higher than that of NCA concrete depending on the strength grade. Such behaviors of RCA concrete are due to the variation in the mix composition (aggregate amount, pozzolanic proportion, cement and RCA contents, etc.) of concrete.

\subsubsection{Permeability}

The permeability of concrete depends on both the absorption capacity of the included aggregate and the permeability of the concrete matrix (cement or binder paste). The permeability of concrete is also affected by its porosity and the size, distribution, and continuity of the pores (Neville 1996). The permeability of RCA concrete appears to be higher than that of NCA concrete for the same water to cement ratio. The permeability of RCA

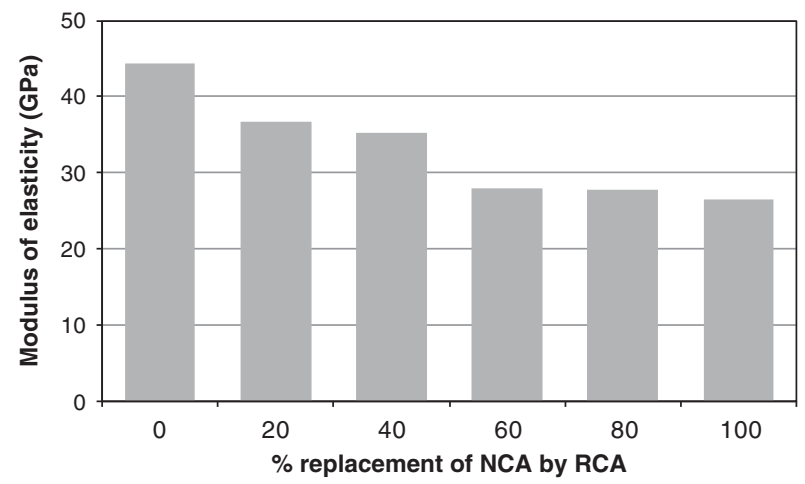

Fig. 4. Effect of RCA on the modulus of elasticity of concrete (Nelson 2004)

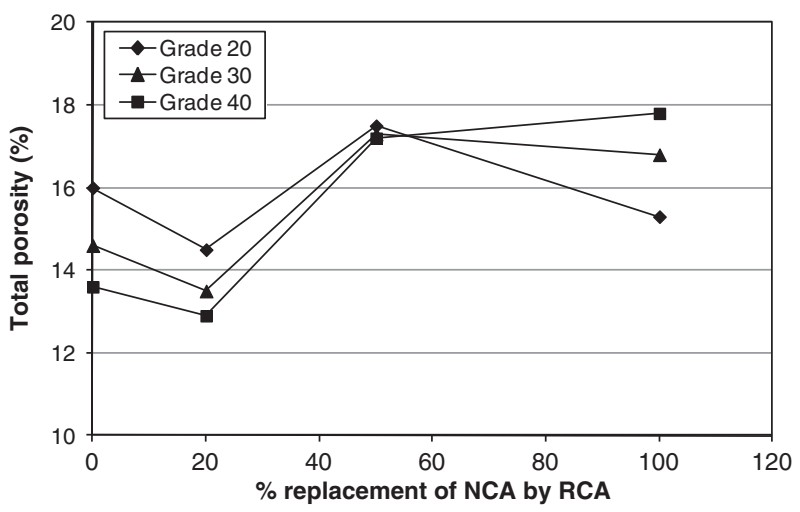

Fig. 5. Effect of RCA on the total porosity of concrete (Levy, Helene 2004)

concrete can be $200-500 \%$ higher than that of NCA concrete (Anderson et al. 2009). If properly accounted for in design, RCA concrete mix can be engineered to have a similar permeability as that of NCA concrete (Tam, V., Tam, C. 2007; ACPA 2009), as shown in Figure 6.

\subsubsection{Water absorption}

Limited investigations have been carried out to determine the water absorption of RCA concrete. In general, the water absorption of RCA concrete is expected to be higher than that of NCA concrete. This is due to the significantly high water absorption and air permeability of RCA. Levy and Helene (2004) made different grades of concrete and showed that, except for $20 \%$ replacement, the water absorption of concrete increased with the increase in RCA content, as evident from Figure 7. According to them, the water absorption of RCA concrete is $0-40 \%$ higher than that of NCA concrete depending on the strength grade. They did not discuss the rationale for lower water absorption at $20 \%$ RCA content, but recommended further investigation.

\subsubsection{Chloride penetration}

Limited studies have been conducted on the chloride penetration resistance of RCA concrete. Tu et al. (2006)

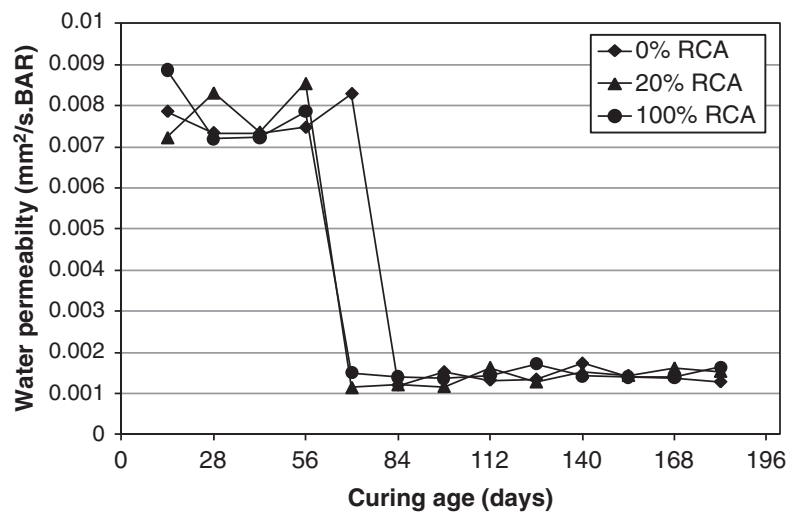

Fig. 6. Effect of RCA on the water permeability of concrete (Tam, V., Tam, C. 2007) 


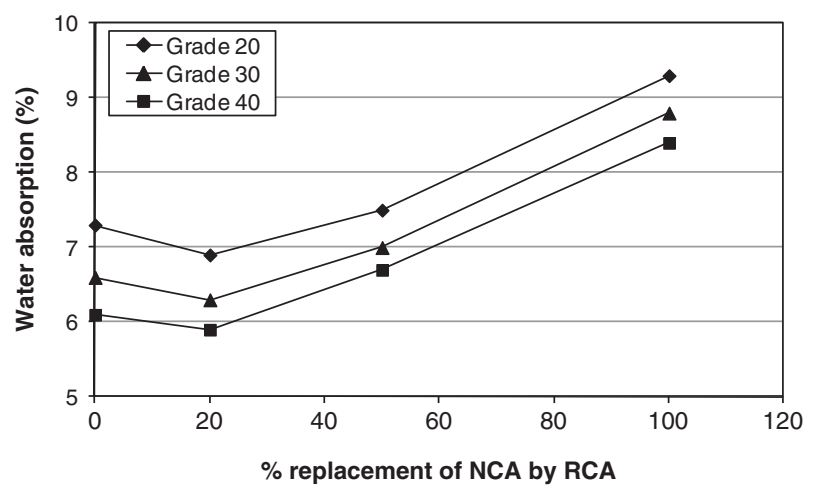

Fig. 7. Effect of RCA on the water absorption of concrete (Levy, Helene 2004)

reported that the chloride penetration values of highperformance concrete made with and without RCA were very similar. According to Corral-Higuera et al. (2011), the use of $100 \%$ RCA in concrete decreases its capacity to resist the penetration of chloride ion by approximately $30 \%$ in comparison with NCA concrete. However, the chloride penetration resistance of RCA concrete can be improved significantly by adding supplementary cementing materials such as fly ash and ground granulated blastfurnace slag. Abbas et al. (2009) revealed that ground granulated blast-furnace slag is more effective than fly ash to enhance the chloride ion penetration resistance of RCA concrete. In their study, the slag reduced the chloride diffusion coefficient of concrete by about $120-200 \%$ as compared to fly ash.

\subsubsection{Drying shrinkage}

Drying shrinkage is primarily a function of paste content and water to cement ratio and restrained by aggregate particles. Since RCA concrete possesses a higher paste content, some studies have reported $20-50 \%$ higher shrinkage than NCA concrete (ACI 555R-01 2001; Anderson et al. 2009). In contrast, few studies reported comparatively lower values of drying shrinkage for RCA concrete. Corinaldesi (2010) observed a lower shrinkage strain at different curing ages of concrete, which was prepared replacing $30 \%$ NCA by RCA (Fig. 8). The

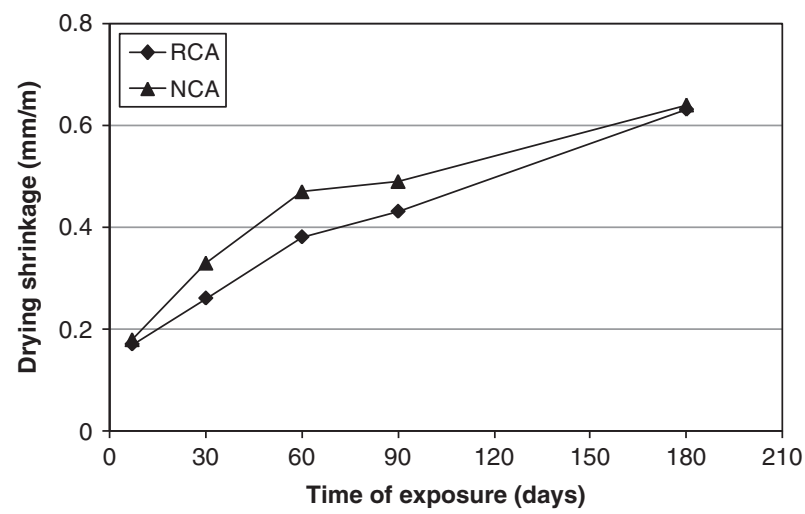

Fig. 8. Effect of RCA on drying shrinkage of concrete (Corinaldesi 2010) conflicting results suggest that more research is desirable to investigate the effect of RCA on the drying shrinkage of concrete.

\subsubsection{Creep}

Limited research work has been carried out on the creep of RCA concrete. The creep of RCA concrete is typically $30-60 \%$ higher than that of NCA concrete (Anderson et al. 2009). This is because creep is proportional to paste content, which can be up to $50 \%$ higher in RCA concrete (ACI 555R-01 2001). Nevertheless, further investigation is vital to confirm the adverse effect of RCA on the creep of concrete.

\subsubsection{Thermal expansion}

Similar to creep, only limited reports are available on the thermal expansion behaviour of RCA concrete. The coefficient of thermal expansion is primarily a function of the type and content of aggregate (ACPA 2009). Wade et al. (1997) reported that the coefficient of thermal expansion of RCA concrete is typically $10-30 \%$ higher than that of NCA concrete. However, more investigations on the effect of RCA on the thermal expansion behaviour of concrete are needed to confirm this finding.

\subsection{Durability}

Durability is the capacity of concrete to resist weathering action, chemical attack, abrasion, and other adverse service conditions. RCA concrete can be highly durable even when the RCA is produced from concrete with durability problems, provided that the mixture proportioning is done properly and good quality is maintained during construction (ECCO 1999). The different durability properties of RCA concrete are discussed hereafter.

\subsubsection{Freeze-thaw resistance}

Several researchers reported that RCA concrete shows adequate resistance to freeze-thaw cycles; surprisingly, there is even evidence that multiple recycling of RCA concrete further improves frost resistance (Malheron, O’Mahony 1988; Hansen 1992; ECCO 1999). However, some researchers mentioned about the same or slightly decreased frost resistance (Hansen 1992; Salem et al. 2003; Zaharieva et al. 2004) for RCA concrete as compared to NCA concrete. Furthermore, the concrete prepared with saturated and dry RCA exhibited poorer freeze-thaw resistance; however, the RCA concrete made with semisaturated aggregates showed better results due to the improved bonding at the interfaces between aggregate and paste (de Oliveira, Vazquez 1996). Nevertheless, more research is needed to confirm the effect of RCA on the freeze-thaw resistance of concrete.

\subsubsection{Sulphate resistance}

Limited research showed that the resistance of RCA concrete to sulphates (found in sea water) is about the 
same or slightly inferior to that of conventional concrete (ECCO 1999). The sulphate resistance of RCA concrete can generally be improved with proper mixture proportioning and by using fly ash, ground granulated blastfurnace slag, or silica fume (ECCO 1999). However, comprehensive research is needed to investigate the sulphate resistance of RCA concrete.

\subsubsection{Resistance to corrosion}

Limited research has been conducted on the corrosion resistance of RCA concrete. The corrosion rate of embedded steel can be slowed down in RCA concrete by proper mixture proportioning and good quality control of construction (ACPA 2009). Ann et al. (2008) used a polarization method to identify the corrosion behavior of steel embedded in RCA concrete. They observed that the corrosion rate did not seem to depend on the type of binder and aggregate for lower level of chlorides $(<0.2-$ $0.3 \%$ by weight of cement), but significantly changed for a higher level of chlorides $(>0.5 \%)$. They also found that RCA concrete with $30 \%$ pulverized fuel ash and $65 \%$ ground granulated blast-furnace slag was more effective in mitigating corrosion reaction at higher level of chlorides, as compared to NCA concrete. Nonetheless, further investigation is required to assess the corrosion resistance of RCA concrete.

\subsubsection{Resistance to carbonation}

The available literature shows the contradictory effects of RCA on the carbonation of concrete. Levy and Helene (2004) found that the carbonation depth decreases when the RCA content increases, presenting a better behavior except for $100 \%$ replacement. According to them, RCA concrete needs a greater cement content to achieve the similar strength of NCA concrete at the same water to cement ratio. The greater cement content has a higher alkali reserve, which acts to decrease the depth of carbonation in concrete. In contrast, Hansen (1992) reported that the carbonation depth of RCA concrete is higher than that of NCA concrete at the same water to cement ratio. Moreover, the rate of carbonation of RCA concrete is four times greater than that of NCA concrete (Hansen 1992). The higher carbonation may increase the risk of corrosion of reinforcing steel in RCA concrete. Such risk can be offset by lower water to cement ratio, proper curing, suitable supplementary cementing material, and increased concrete cover. Nevertheless, more research is needed to evaluate the effect of RCA on the carbonation resistance of concrete.

\subsubsection{Resistance to alkali-silica reaction}

Inadequate investigations have been conducted to assess the performance of RCA concrete against alkali-silica reaction. The resistance of RCA concrete to alkali-silica reaction depends on the source of RCA. Stark (1996) reported that the RCA derived from old concrete containing alkali affects the resistance of newly developed RCA concrete to alkali-silica reaction. His results indicated that the new concrete made with RCA expanded excessively due to alkali-silica reaction. The use of low-lime Class-F fly ash can greatly reduce the expansion due to alkalisilica reaction in RCA concrete (ECCO 1999). The available data are insufficient to draw a certain conclusion on the alkali-silica reactivity of RCA concrete and therefore further investigation is required.

\subsubsection{Resistance to acid attack}

Limited literatures are available on the durability of RCA concrete under acid attack. Morgan (2009) reported that the resistance of RCA concrete to acid attack is equal to or slightly inferior to that of NCA concrete. To evaluate the degree of deterioration of RCA concrete against acid attack, he immersed the concrete samples in a testing bath containing $\mathrm{H}_{2} \mathrm{SO}_{4}$ with a $\mathrm{pH}$ of 2 . The acid penetration into the RCA concrete was slightly higher than that of NCA concrete. However, he showed that the resistance of RCA concrete to acid attack can be improved by the addition of fly ash (Morgan 2009). Due to limited research, further investigation of RCA concrete exposed to acidic environment is required to evaluate its durability characteristic.

\section{Factors affecting the properties of RCA concrete}

The properties of RCA concrete are influenced by several key factors such as water to cement ratio, RCA content, the type and size of RCA, the physical characteristics of $\mathrm{RCA}$, the quality of the parent concrete of RCA, the moisture condition of RCA, curing condition, cement content, and air entrainment (Tavakoli, Soroushian 1996). These factors are discussed below.

\subsection{Properties of RCA}

The physical properties of RCA significantly influence the fresh and hardened properties of concrete. For instance, the fresh concrete mixes with angular and rough-textured RCA particles become harsh and therefore are difficult to finish; the workability and finishability of concrete can also be affected due to the high absorption of RCA (Anderson et al. 2009). In addition, the higher pore volume of RCA can affect the porosity, strength, and transport properties (water absorption, permeability, etc.) of concrete (Safiuddin et al. 2011a).

\subsection{RCA content}

The fresh and hardened properties of concrete are greatly influenced by the RCA content used as a partial or full replacement of NCA. Cabral et al. (2010) developed a model using seven independent variables (with respect to the type and amount of aggregates) to predict concrete's performance for $0 \%$ to $100 \%$ replacement of NCA with RCA. They found that the concrete produced with RCA had lower compressive strength and elastic modulus than NCA concrete. Also, higher RCA content increases water absorption but decreases density, thus leading to increased porousness in concrete. The use of $50 \%$ and $100 \%$ coarse RCA increases the water absorption and decreases the 
density of concrete by about $0.15-0.37 \%$ and $2.12-$ $3.40 \%$, respectively (Grdic et al. 2010). In addition, Kou and Poon (2009) reported that the compressive and tensile splitting strengths of concrete decreased, whereas the resistance to chloride-ion penetration increased with an increase in fine RCA content. They also observed that the drying shrinkage of concrete increased with an increase in RCA content, but it can be controlled by using lower water to cement ratio.

\subsection{Quality of parent concrete}

Padmini et al. (2009) investigated the influence of parent concrete quality on the properties of RCA concrete. They observed that the water absorption of RCA increases with the increased strength of parent concrete. This is because the concrete with higher strength generally requires a greater cement content, thus increasing the quantity of mortar adhering to the aggregates. Therefore, the adjustment of mix water content is mandatory for the new concrete including the RCA derived from an old concrete of higher strength to obtain the desired workability. The porous RCA affects the strength of RCA concrete. The percentage loss in the compressive or tensile strength of new concrete due to the use of RCA is more significant when it is derived from a weak old concrete than a stronger old concrete (Tabsh, Abdelfatah 2009). More research is required to evaluate the effect of the quality of parent concrete on RCA concrete properties.

\subsection{Type or source of RCA}

Limited studies have been carried out to investigate the effect of the type or source of RCA on concrete properties. According to Cabral et al. (2010), the concrete produced with coarse RCA had a lower compressive strength, except for the concrete made of recycled fine aggregate derived from brick ceramic, where an increase in compressive strength was observed. The elastic modulus of concrete was reduced for all types of RCA. However, the RCA obtained from red ceramic exerted a larger influence in reducing concrete's elastic modulus due to lower density. Further research is needed to assess the effect of the type or source of RCA on different concrete properties.

\subsection{Size of RCA}

Limited investigations were conducted to observe the size effect of RCA on concrete properties. Padmini et al. (2009) used three different aggregate sizes to assess the influence of RCA size on the properties of concrete. The higher reduction in the modulus of elasticity was obtained for the concrete made with a smaller size of RCA. In contrast, they found that the strength increases with an increase in the maximum size of RCA. They also found that the water absorption of concrete decreases with an increase in the maximum size of RCA. This is due to the relatively low content of weaker mortar adhered to larger-sized aggregates. Additional research is necessitated to investigate the size effect of RCA on different concrete properties.

\subsection{Moisture condition of RCA}

The moisture condition of aggregates affects the workability of concrete. The initial slump (a measurement of workability) of concrete is strongly dependent on the initial free water content of the concrete mix. However, very few studies have been carried out to investigate the effect of RCA moisture conditions on the fresh properties of concrete. Poon et al. (2004) reported that the oven-dry RCA leads to a higher initial slump and quicker slump loss, while the saturated surface-dry and air-dry RCAs show normal initial slump and slump loss. More research is needed to examine the effect of RCA moisture condition on the properties of fresh and hardened concretes.

\subsection{Curing condition}

The outer environmental curing conditions produce the more adverse effects on RCA concrete than on NCA concrete. Fonseca et al. (2011) reported that the difference in the splitting tensile strength between NCA and RCA concretes is high when they are cured in the outer environment. Moreover, Buyle-Bodin and HadjievaZaharieva (2002) reported that the depth of carbonation of water-cured RCA concrete is almost twice smaller than that of air-cured RCA concrete. The decrease in the depth of carbonation produced by water curing might be partially due to higher internal humidity of concrete. Further research is required to assess the effect of different curing conditions on the performance of RCA concrete.

\subsection{Cement content}

Limited literatures are available on the effect of cement content on the properties of RCA concrete. The RCA concrete with high cement content was found to have high resistance to carbonation (Abbas et al. 2009). Padmini et al. (2009) recommended higher cement content for RCA concrete to achieve a desired compressive strength. According to Sagoe-Crentsil et al. (2001), the tensile resistance of RCA concrete increases with the increased cement content in concrete.

\subsection{Water to cement ratio}

The decline in the performance of RCA concrete is related to the water to cement ratio used in mix design (BuyleBodin, Hadjieva-Zaharieva 2002). Padmini et al. (2009) found that RCA concrete requires lower water to cement ratio and higher cement content as compared to the parent concrete of RCA to achieve a particular compressive strength. At a water to cement ratio of 0.29 , the resistance of NCA concrete to freezing and thawing was extremely high but the same water to cement ratio failed to provide an acceptable freeze-thaw resistance for RCA concrete (Salem et al. 2003).

\subsection{Air entrainment}

Limited investigations have been carried out to study the effect of air entrainment on the performance of RCA 
concrete. Durable RCA concrete can be produced through proper air entrainment. The air entrainment is as effective for RCA concrete as for NCA concrete. Moreover, the use of entrained air is more effective than lowering the water to cement ratio to improve the resistance of RCA concrete to freezing and thawing (Salem et al. 2003). Comprehensive research is needed to evaluate the performance of air-entrained RCA concrete.

\section{Methods to enhance the performance of RCA concrete}

\subsection{Improvement of RCA quality}

Larbi et al. (2000) tried a thermal treatment method to improve the quality of RCA, and they found that after thermal treatment at $800{ }^{\circ} \mathrm{C}$, the RCA was reasonably comparable to the conventionally used river-dredged aggregates. Chen et al. (2003) found that the strength of concrete was affected by the unwashed RCA used in the concrete mix. However, the use of washed RCA negated the strength reduction.

\subsection{Adjustment of water to cement ratio}

Mandal et al. (2002) stated that the proper adjustment of water to cement ratio for the concrete mix could improve the strength of RCA concrete. As stated earlier, Padmini et al. (2009) recommended lower water to cement ratio and higher cement content for RCA concrete than those of the parent concrete of RCA to achieve identical compressive strength. Similarly, Salem et al. (2003) reported that lowering the water to cement ratio to a certain level was highly beneficial for RCA concrete to develop the freezing and thawing resistance equal to that of $\mathrm{NCA}$ concrete.

\subsection{Incorporation of pozzolanic materials}

The strength and durability of RCA concrete can be improved by using suitable pozzolanic materials (Takehiro, Masanori 2000; Mandal et al. 2002; Poon et al. 2002). Ann et al. (2008) showed that the use of $30 \%$ pulverized fly ash and $65 \%$ ground granulated blastfurnace slag increased the compressive strength of RCA concrete to the level of control concrete cast with natural granite gravel; pulverized fuel ash and ground granulated blast-furnace slag were also effective in raising the resistance to chloride-ion penetration into RCA concrete. In addition, it was found that silica fume is effective to significantly increase the chloride-ion penetration resistance of RCA concrete (Corral-Higuera et al. 2011).

\subsection{Use of new mixing technique}

Li et al. (2009) applied a two-stage mixing technique to obtain good-quality RCA concrete. They used recycled aggregate coated with pozzolanic powder to improve the properties of RCA concrete. Tam et al. (2006) also developed a two-stage mixing approach for promoting RCA concrete in higher-grade application. They found that the $100 \%$ NCA replacement is possible by their mixing technique to produce RCA concrete with acceptable properties compared to NCA concrete, though the optimal situation occurs with $20 \%$ replacement of NCA. The slump and strength results suggested that the new mixing technique contributes significantly to achieve better workability and higher compressive and flexural strengths. Furthermore, the interfacial transition zone of RCA concrete was observed by a scanning electron microscope (SEM). The SEM results confirmed that the new mixing technique contributes to a dense microstructure. In addition, the inner bleeding can be reduced by the new mixing technique.

\subsection{Extended curing approach}

Another way of improving the performance of RCA concrete is by employing an extended curing in a wet environment. Extended curing seems to be one of the most practical methods to decrease the carbonation rate of RCA concrete (Buyle-Bodin, Hadjieva-Zaharieva 2002). The depth of carbonation in RCA concrete is almost two times lesser when the concrete is cured with water.

\subsection{Soaking of RCA in mix water or pozzolanic liquid}

The strength of RCA concrete can be improved by either soaking the RCA in mix water/pozzolanic liquid (such as colloidal silica) before concrete mixing or allowing recycled aggregate to soak up a part of mixing water with or without pozzolanic liquid during mixing. The absorbed water or pozzolanic liquid is expected to fill up the micro cracks in RCA with cement gel during cement hydration or pozzolanic reaction (Masanori, Takehiro 2000). Thus, the strength of RCA concrete can be improved.

\section{Research needs}

Though RCA can be used to a certain replacement level of NCA without significant adverse effects on the fresh, hardened, and durability properties of concrete, further investigations are needed to confirm the beneficial effects of RCA for more potential applications. After conducting a critical and thorough review, the following research needs have been identified:

- Investigation on the effect of RCA on the plastic shrinkage, rheological properties (yield stress and plastic viscosity), and segregation resistance of concrete;

- Examination of the effect of RCA on the shear, impact, and bond strengths of concrete;

- Investigation on the fatigue performance of RCA concrete and analysis of its fatigue reliability to facilitate the design of concrete structures subjected to cyclic load;

- Assessment of the electrical resistivity and gas/ oxygen permeability of RCA concrete;

- More investigation of the specific effect of RCA on the splitting tensile strength, drying shrinkage, and creep of concrete; 
- More investigation for assessing the effect of RCA on the water absorption, porosity, chloride penetration resistance, and thermal expansion of concrete;

- Comprehensive study for examining the effect of RCA on the durability performance of concrete with respect to resistances to freezing and thawing, sulphate attack, corrosion, carbonation, alkalisilica reaction, and acid attack;

- Investigation on the potential use of RCA in the production of high-strength, high-performance, lightweight, and self-consolidating concretes;

- More study on the effect of quality of the parent concrete of RCA, the moisture condition of RCA, and the adhered mortar/cement content of RCA on the properties of new concrete;

- Investigation on the effect of different types or sources and particle sizes of RCA on the properties of concrete;

- Investigation on the effectiveness of existing mixing techniques or development of new mixing techniques to enhance the performance of RCA concrete.

\section{Concluding remarks}

There is a significant potential of recycling demolished concrete for use in value-added applications to maximize economic and environmental benefits. Significant savings can be achieved through converting RCA into useful resources in the production of new concrete. The present study has critically reviewed the properties of RCA and RCA concrete. The following conclusions are made from this study:

- RCA is useful as a substitute of NCA to produce concrete with acceptable properties and durability. However, the main problem of using RCA in new concrete is its inconsistent quality, particularly when it is obtained through demolition of old concrete structures;

- RCA can be successfully used in new concrete by meeting the standard specifications for natural aggregate. However, new specifications and guidelines are needed for RCA;

- The physical properties of RCA significantly influence the fresh and hardened properties of concrete. The aggregate abrasion, impact, and crushing values of RCA affect the strength properties of concrete. Moreover, the adverse chemical properties of RCA can affect the durability of RCA concrete and thus its performance in service conditions;

- The use of $100 \%$ RCA is possible to produce concrete with acceptable quality. The concrete produced with RCA has generally $80-90 \%$ of the strength of a comparable NCA concrete. The reduction in the strength of RCA concrete is caused by the adverse physical properties of
RCA and inadequately dense transition zone between RCA and bulk cement paste;

- The use of fine RCA in a new concrete mix requires careful examination, as the recycled fines further reduce the strength of concrete. In general, the replacement of virgin sand by recycled fines up to $20 \%$ is acceptable;

- The performance of RCA concrete can be enhanced by adjusting water to cement ratio, incorporating pozzolanic materials, using new mixing techniques, and employing extended curing;

- RCA can be used in high-quality concretes such as high-strength, high-performance, and selfconsolidating concretes by appropriate materials selection and mix design.

Despite the differences in properties between RCA and $\mathrm{NCA}$, the concrete containing RCA can be properly designed and proportioned to minimize the impact of RCA on its fresh and hardened properties and durability. In addition, the chemical contaminants in RCA should be minimized to encourage its usage in concrete industry.

\section{Acknowledgment}

The authors gratefully acknowledge the financial support from the University of Malaya Research Grant (UMRG) under Grant No. RP 018/2012A AET.

\section{References}

Abbas, A.; Fathifazl, G.; Isgor, O. B.; Razaqpur, A. G.; Fournier, B.; Foo, S. 2009. Durability of recycled aggregate concrete designed with equivalent mortar volume method, Cement and Concrete Composites 31(8): 555-563.

http://dx.doi.org/10.1016/j.cemconcomp.2009.02.012

ACI 555R-01. 2001. Removal and reuse of hardened concrete. ACI manual of concrete practice, part 6 . Farmington Hills, MI: American Concrete Institute. 26 p.

ACPA. 2009. Properties of concrete containing RCA [online], [cited 2 May 2011]. Available from Internet: http://www.pavement.com/Downloads/TS/EB043P/TS043. 5P.pdf.

Ajdukiewicz, A.; Kliszczewicz, A. 2002. Influence of recycled aggregates on mechanical properties of HS/HPC, Cement and Concrete Composites 24(2): 269-279. http://dx.doi.org/10.1016/S0958-9465(01)00012-9

Anderson, K. W.; Uhlmeyer, J. S.; Russell, M. 2009. Use of recycled concrete aggregate in PCCP: literature search. WSDOT Research Report WA-RD 726.1. Olympia, WA: Washington State Department of Transportation (WSDOT). $37 \mathrm{p}$.

Ann, K. Y.; Moon, H. Y.; Kim, Y. B.; Ryou, J. 2008. Durability of recycled aggregate concrete using pozzolanic materials, Waste Management 28(6): 993-999. http://dx.doi.org/10.1016/j.wasman.2007.03.003

ASTM C 33-04. 2004. Standard specification for concrete aggregates. Annual Book of ASTM Standards, Vol. 04.02. Philadelphia, PA: American Society for Testing Materials.

Butler, L.; West, J. S.; Tighe, S. L. 2011. The effect of recycled concrete aggregate properties on the bond strength between RCA concrete and steel reinforcement, Cement and Concrete Research 41(10): 1037-1049. http://dx.doi.org/10.1016/j.cemconres.2011.06.004 
Buyle-Bodin, F.; Hadjieva-Zaharieva, R. 2002. Influence of industrially produced recycled aggregates on flow properties of concrete, Materials and Structures 35(8): 504-509. http://dx.doi.org/10.1007/BF02483138

Cabral, A. E. B.; Schalch, V.; Molin, D. C. C. D.; Ribeiro, J. L. D. 2010. Mechanical properties modeling of recycled aggregate concrete, Construction and Building Materials 24(4): 421-430.

http://dx.doi.org/10.1016/j.conbuildmat.2009.10.011

Chen, H.-J.; Yen, T.; Chen, K.-H. 2003. Use of building rubbles as recycled aggregates, Cement and Concrete Research 33(1): 125-132.

http://dx.doi.org/10.1016/S0008-8846(02)00938-9

Chern, J. C.; Hwang, C. L.; Tsai, D. H. 1995. Research and development of HPC in Taiwan, Concrete International 17(10): 71-76.

Corinaldesi, V. 2010. Mechanical and elastic behaviour of concretes made of recycled-concrete coarse aggregates, Construction and Building Materials 24(9): 1616-1620. http://dx.doi.org/10.1016/j.conbuildmat.2010.02.031

Corral-Higuera, R.; Arredondo-Rea, S. P.; Neri-Flores, M. A.; Gómez-Soberón, J. M.; Almaral-Sánchez, J. L.; CastorenaGonzález, J. H.; Martínez-Villafañe, A.; Almeraya-Calderón, F. 2011. Chloride ion penetrability and corrosion behavior of steel in concrete with sustainability characteristics, International Journal of Electrochemical Science 6: 958-970.

de Oliveira, M. B.; Vazquez, E. 1996. The influence of retained moisture in aggregates from recycling on the properties of new hardened concrete, Waste Management 16(1-3): 113-117.

http://dx.doi.org/10.1016/S0956-053X(96)00033-5

Dhir, R. K.; Limbachiya, M. C.; Leelawat, T. 1999. Suitability of recycled aggregate for use in BS 5328 designated mixes, in Proc. of the Institution of Civil Engineers: Structures and Buildings, London, 257-274. http://dx.doi.org/10.1680/istbu.1999.31568

ECCO. 1999. Recycling concrete and masonry [online], [cited 2 May 2011]. Skokie, IL: Environmental Council of Concrete Organization. Available from Internet: http://www.p2pays.org/ref/14/13608.pdf.

Evangelista, L.; de Brito, J. 2007. Mechanical behaviour of concrete made with fine recycled concrete aggregates, Cement and Concrete Composites 29(5): 397-401. http://dx.doi.org/10.1016/j.cemconcomp.2006.12.004

Fonseca, N.; de Brito, J.; Evangelista, L. 2011. The influence of curing conditions on the mechanical performance of concrete made with recycled concrete waste, Cement and Concrete Composites 33(6): 637-643. http://dx.doi.org/10.1016/j.cemconcomp.2011.04.002

Frondistou-Yannas, S. 1977. Waste concrete as aggregate for new concrete, ACI Journal Proceedings 74(8): 373-376.

González-Fonteboa, B.; Martínez-Abella, F. 2008. Concretes with aggregates from demolition waste and silica fume. Materials and mechanical properties, Building and Environment 43(4): 429-437. http://dx.doi.org/10.1016/j.buildenv.2007.01.008

Grdic, Z. J.; Toplicic-Curcic, G. A.; Despotovic, I. M.; Ristic, N. S. 2010. Properties of self-compacting concrete prepared with coarse recycled concrete aggregate, Construction and Building Materials 24(7): 1129-1133. http://dx.doi.org/10.1016/j.conbuildmat.2009.12.029

Hansen, T. C. 1986. Recycled aggregates and recycled aggregate concrete: second state-of-the-art report, developments 1945-1985, Materials and Structures 19(3): 201-246. http://dx.doi.org/10.1007/BF02472036
Hansen, T. C. 1992. Recycling of demolished concrete and masonry. Oxfordshire: Taylor \& Francis. 336 p.

Hansen, T. C.; Narud, H. 1983. Strength of recycled concrete made from crushed concrete coarse aggregate, Concrete International 5(1): 79-83.

Hassan, M. N.; Yusoff, M. K.; Sulaiman, W. N. A.; Rahman, R. A. 1998. Issues and problems of solid waste management in Malaysia, in Proc. on National Review on Environmental Quality Management in Malaysia: Towards the Next Two Decades, 1998, Bangi, Selangor Darul Ehsan, Malaysia: Institute for Environment and Development (LESTARI), UKM.

Hendriks, C. F.; Pieterson, H. S. 1998. Concrete: durable but also sustainable, in Proc. of the International Conference on the Use of Recycled Concrete Aggregates, 1998, Thomas Telford, London, UK, 1-18.

Hwang, C. L.; Liu, J. J.; Lee, L. S.; Lin, F. Y. 1996. Densified mixture design algorithm and early properties of highperformance concrete, Journal of the Chinese Institute of Civil and Hydraulic Engineering 8(2): 217-219.

Juan, M. S.; Gutierrez, P. A. 2004. Influence of recycled aggregate quality on concrete properties, in Proc. of the International RILEM Conference: The Use of Recycled Materials in Building and Structure, 2004, Barcelona, Spain, 545-553.

Khalaf, F. M.; DeVenny, A. S. 2004. Recycling of demolished masonry rubble as coarse aggregate in concrete: review, Journal of Materials in Civil Engineering 16(4): 331-340. http://dx.doi.org/10.1061/(ASCE)0899-1561(2004)16:4(331)

Kou, S. C.; Poon, C. S. 2009. Properties of self-compacting concrete prepared with coarse and fine recycled concrete aggregates, Cement and Concrete Composites 31(9): 622627. http://dx.doi.org/10.1016/j.cemconcomp.2009.06.005

Larbi, J. A.; Heijnen, W. M. M.; Brouwer, J. P.; Mu, E. 2000. Preliminary laboratory investigation of thermal treated recycled concrete aggregate for general use in concrete, in G. R. Wooley and G. Wainwright. Waste Materials in Construction-WASCON. Pergamon, England, 129-139.

Levy, S. M.; Helene, P. 2004. Durability of recycled aggregates concrete: a safe way to sustainable development, Cement and Concrete Research 34(11): 1975-1980. http://dx.doi.org/10.1016/j.cemconres.2004.02.009

Li, J.; Xiao, H.; Zhou, Y. 2009. Influence of coating recycled aggregate surface with pozzolanic powder on properties of recycled aggregate concrete, Construction and Building Materials 23(3): 1287-1291. http://dx.doi.org/10.1016/j.conbuildmat.2008.07.019

Li, L. S.; Hwang, C. L. 2002. A quality assurance system of $\mathrm{SCC}$ in Taiwan, in Proc. of the First North American Conference on the Design and Use of Consolidating Concrete, 2002, Chicago, USA, 275-280.

Limbachiya, M. C.; Koulouris, A.; Roberts, J. J.; Fried, A. N. 2004. Performance of recycled aggregate concrete, in Proc. of RILEM International Symposium on EnvironmentConscious Materials and Systems for Sustainable Development, 2004, Koriyama, Japan, 127-136.

Limbachiya, M. C.; Leelawat, T.; Dhir, R. K. 2000. Use of recycled concrete aggregate in high-strength concrete, Materials and Structures 33(9): 574-580. http://dx.doi.org/10.1007/BF02480538

López-Gayarre, F.; Serna, P.; Domingo-Cabo, A.; SerranoLópez, M. A.; López-Colina, C. 2009. Influence of recycled aggregate quality and proportioning criteria on recycled concrete properties, Waste Management 29(12): 3022-3028.

http://dx.doi.org/10.1016/j.wasman.2009.07.010 
Malešev, M.; Radonjanin, V.; Marinković, S. 2010. Recycled concrete as aggregate for structural concrete production, Sustainability 2: 1204-1225. http://dx.doi.org/10.3390/su2051204

Malheron, M.; O'Mahony, M. 1988. The durability of recycled aggregates and recycled aggregate concrete, in Proc. of the Second International RILEM Symposium, 1988, Tokyo, Japan, 633-642.

Mandal, S.; Chakraborty, S.; Gupta, A. 2002. Some studies on durability of recycled aggregate concre, Indian Concrete Journal 76(6): 385-388.

Masanori, T.; Takehiro, S. 2000. New technique producing recycled aggregate concrete for conservation of resources and energy, Transaction of Japan Concrete Institute 22: $77-84$.

Morgan. 2009. Recycled concrete [online], [cited 20 June 2011]. Availabe from Internet: http:/www.careers-india.com/2009/09/22/recycled-concrete/ \#ixzz1P0RBYjDT

Mukai, T.; Kikuchi, M.; Koizumi, H. 1979. Study on reuse of waste concrete for aggregate of concrete, Paper presented at a seminar on "Energy and Resources Consevation in Concrete Technology", Japan-US Coopeartive Science Programme, San Francisco, USA.

Nelson, S. C. N. 2004. High-strength structural concrete with recycled aggregates: BSc Engineering Thesis. Queensland: University of Southern Queensland. $100 \mathrm{p}$.

Neville, A. M. 1996. Properties of concrete. 4th ed. New York: John Wiley \& Sons, Inc. 844 p.

Padmini, A. K.; Ramamurthy, K.; Mathews, M. S. 2009. Influence of parent concrete on the properties of recycled aggregate concrete, Construction and Building Materials 23(2): 829-836.

http://dx.doi.org/10.1016/j.conbuildmat.2008.03.006

Poon, C. S.; Azhar, S.; Kou, S. C. 2003. Recycled aggregates for concrete applications, in Proc. of the Materials Science and Technology in Engineering Conference-Now, New and Next, 2003, Hong Kong, China.

Poon, C. S.; Chan, D. 2007. Effects of contaminants on the properties of concrete paving blocks prepared with recycled concrete aggregates, Construction and Building Materials 21(1): 164-175.

http://dx.doi.org/10.1016/j.conbuildmat.2005.06.031

Poon, C. S.; Kou, S. C.; Lam, L. 2002. Use of recycled aggregates in molded concrete bricks and blocks, Construction and Building Materials 16(5): 281-289. http://dx.doi.org/10.1016/S0950-0618(02)00019-3

Poon, C. S.; Shui, Z. H.; Lam, L.; Fok, H.; Kou, S. C. 2004. Influence of moisture states of natural and recycled aggregates on the slump and compressive strength of concrete, Cement and Concrete Research 34(1): 31-36. http://dx.doi.org/10.1016/S0008-8846(03)00186-8

Rahal, K. 2007. Mechanical properties of concrete with recycled coarse aggregate, Building and Environment 42(1): 407415. http://dx.doi.org/10.1016/j.buildenv.2005.07.033

Safiuddin, Md.; Alengaram, U. J.; Salam, M. A.; Jumaat, M. Z.; Jaafar, F. F.; Saad, H. B. 2011a. Properties of highworkability concrete with recycled concrete aggregate, Materials Research 14(2): 1-8. http://dx.doi.org/10.1590/S1516-14392011005000039

Safiuddin, Md.; Salam, M. A.; Jumaat, M. Z. 2011b. Effects of recycled concrete aggregate on the fresh properties of selfconsolidating concrete, Archives of Civil and Mechanical Engineering 11(4): 1023-1041. http://dx.doi.org/10.1016/S1644-9665(12)60093-4
Safiuddin, Md.; West, J. S.; Soudki, K. A. 2011c. Air content of self-consolidating concrete and its mortar phase including rice husk ash, Journal of Civil Engineering and Management 17(3): 319-329.

http://dx.doi.org/10.3846/13923730.2011.589225

Sagoe-Crentsil, K. K.; Brown, T.; Taylor, A. H. 2001. Performance of concrete made with commercially produced coarse recycled concrete aggregate, Cement and Concrete Research 31(5): 707-712.

http://dx.doi.org/10.1016/S0008-8846(00)00476-2

Salem, R. M.; Burdette, E. G.; Jackson, N. M. 2003. Resistance to freezing and thawing of recycled aggregate concrete, ACI Materials Journal 100(3): 216-221.

Shayan, A.; Xu, A. 2003. Performance and properties of structural concrete made with recycled concrete aggregate, ACI Materials Journal 100(5): 371-380.

Siwar, C. 2008. Solid waste management: recycling, green jobs and challenges in Malaysia, in Presentation in ILO Research Conference: Green Jobs for Asia \& Pacific, Niigata, Japan.

Snyder, M. B.; Vandenbossche, J. M. 1993. New research and practice in the recycling of concrete, Paper presented in Concrete Technology Seminars-7: The Evolving World of Concrete, Michigan State University, East Lansing, Michigan, USA.

Stark, D. 1996. The use of recycled-concrete aggregate from concrete exhibiting alkali-silica reactivity. Skokie, IL: Research and Development Bulletin AD114, Portland Cement Association.

$\mathrm{Su}, \mathrm{N}$.; Wang, B. L. 2000. Study on the engineering properties of recycled aggregate concrete and recovered aggregate from demolished concrete, Journal of the Chinese Institute of Civil and Hydraulic Engineering 12(3): 435-444.

Tabsh, S. W.; Abdelfatah, A. S. 2009. Influence of recycled concrete aggregates on strength properties of concrete, Construction and Building Materials 23(2): 1163-1167.

http://dx.doi.org/10.1016/j.conbuildmat.2008.06.007

Takehiro, S.; Masanori, T. 2000. Technique to produce recycled aggregate concrete with crushed concrete waste, Journal of the Society of Materials Science, Japan 49(10): 10791084. http://dx.doi.org/10.2472/jsms.49.1079

Tam, V. W. Y.; Gao, X. F.; Tam, C. M. 2006. Environmental enhancement through use of recycled aggregate concrete in a two-stage mixing approach, Journal of Human and Ecological Risk Assessment 12(2): 277-288. http://dx.doi.org/10.1080/10807030500531653

Tam, V. W. Y.; Tam, C. M. 2007. Assessment of durability of recycled aggregate concrete produced by two-stage mixing approach, Journal of Materials Science 42(10): 35923602. http://dx.doi.org/10.1007/s10853-006-0379-y

Tavakoli, M.; Soroushian, P. 1996. Strengths of recycled aggregate concrete made using field-demolished concrete as aggregate, ACI Material Journal 93(2): 182-190.

Topçu, I. B.; Günçan, N. F. 1995. Using waste concrete as aggregate, Cement and Concrete Research 25(7): 13851390. http://dx.doi.org/10.1016/0008-8846(95)00131-U

Tu, T.-Y.; Chen, Y.-Y.; Hwang, C.-L. 2006. Properties of HPC with recycled aggregates, Cement and Concrete Research 36(5): 943-950.

http://dx.doi.org/10.1016/j.cemconres.2005.11.022

Wade, M. J.; Cuttell, G. D.; Vandenbossche, J. M.; Yu, H. T.; Smith, K. D.; Snyder, M. B. 1997. Performance of concrete pavements containing recycled concrete aggregate. FHWA-RD-96-164, Federal Highway Administration, US Department of Transportation, Washington, USA. 
Yang, K. H.; Chung, H. S.; Ashraf, A. F. 2008. Influence of type and replacement level of recycled aggregates on concrete properties, ACI Materials Journal 105(3): 289-296.

Yong, P. C.; Teo, D. C. L. 2009. Utilisation of recycled aggregate as coarse aggregate in concrete, UNIMAS E-Journal of Civil Engineering 1(1): 1-6.

Yrjanson, W. 1989. Recycling of portland cement concrete pavements. Synthesis of highway practice 154. National Cooperative Highway Research Program. Transportation Research Board, National Research Council, Washington, USA.
Zaharieva, R.; Buyle-Bodin, F.; Wirquin, E. 2004. Frost resistance of recycled aggregate concrete, Cement and Concrete Research 34(10): 1927-1932. http://dx.doi.org/10.1016/j.cemconres.2004.02.025

Zhou, F. P.; Lydon, F. D.; Barr, B. I. G. 1995. Effect of coarse aggregate on elastic modulus and compressive strength of high performance concrete, Cement and Concrete Research 25(1): 177-186. http://dx.doi.org/10.1016/0008-8846(94)00125-I

Md. SAFIUDDIN. Professor in the school of Construction Management and Trades, Centre for Construction and Engineering Technologies, George Brown College, Toronto, Ontario, Canada. He is a member of Professional Engineers Ontario, American Concrete Institute, and Bangladesh Environmental Network. He is also a lifetime fellow of Institution of Engineers, Bangladesh. His research interests include concrete materials, high strength and high performance concretes, self-consolidating concrete, green or sustainable concrete, durability of concrete, utilization of waste materials in concrete, and repair and rehabilitation of concrete structures.

Ubagaram Johnson ALENGARAM. Senior Lecturer in the Department of Civil Engineering, Faculty of Engineering, University of Malaya, Kuala Lumpur, Malaysia. He is a registered Chartered Engineer of the Institution of Civil Engineers (UK) and The Engineering Council (UK). His research interests include the material, durability and structural aspects of lightweight concrete, development of sustainable geo-polymer concrete, and utilization lightweight waste materials in concrete.

Md. Moshiur RAHMAN. PhD Candidate and Graduate Research Assistant in the Department of Civil Engineering, Faculty of Engineering, University of Malaya, Kuala Lumpur, Malaysia. He is a registered professional engineer in Bangladesh. His research interests include concrete materials, strengthening of reinforced concrete members, and structural optimization.

Md. Abdus SALAM. Assistant Professor in the Department of Civil Engineering, Dhaka University of Engineering and Technology (DUET), Gazipur, Bangladesh. He is a member of Institution of Engineers, Bangladesh. His research interests include concrete materials, self-consolidating concrete, and green or sustainable concrete.

Mohd. Zamin JUMAAT. Professor in the Department of Civil Engineering, Faculty of Engineering, University of Malaya, Kuala Lumpur, Malaysia. He is a council member of the Institution of Engineers, Malaysia and a member of the Drafting Code Committee for Reinforced Concrete Structures. His research interests include concrete materials, self-consolidating concrete, lightweight concrete, green or sustainable concrete, and behavior of structural concrete elements. 